\title{
Haemodynamic effects of salbutamol in patients with acute myocardial infarction and severe left ventricular dysfunction
}

\author{
ADAM D TIMMIS, SARKIES K STRAK, DOUGLAS A CHAMBERLAIN
}

British Medical fournal, 1979, 2, 1101-1103

\section{Summary and conclusions}

The haemodynamic effects of salbutamol infusions at rates of 10,20 , and $40 \mu \mathrm{g} / \mathrm{min}$ were measured in 11 patients with acute myocardial infarction complicated by left ventricular failure. Four patients also had cardiogenic shock. Consistent increases were observed in cardiac outputs at all doses (up to $56 \%$ at $40 \mu \mathrm{g} / \mathrm{min}$ ), while the mean systemic arterial pressure fell slightly (average $5 \mathrm{~mm} \mathrm{Hg}$ ), implying a reduction in peripheral vascular resistance. Changes in right atrial pressure and indirect left atrial pressure (measured as pulmonary artery end-diastolic pressure) were small and not significant. Analysis of data from individual patients showed that the greatest increment in cardiac output was reached at $10 \mu \mathrm{g} / \mathrm{min}$ in two cases, $20 \mu \mathrm{g} / \mathrm{min}$ in three, and $40 \mu \mathrm{g} / \mathrm{min}$ in the remaining six. Heart rate at these doses increased by an average of only 10 beats $/ \mathrm{min}$.

Salbutamol failed to reduce left ventricular filling pressure and cannot be recommended for the treatment of pulmonary oedema in acute myocardial infarction. The increase in cardiac output, however, was considerable, so that the drug may be important in the management of low-output states. This action is probably a result of peripheral arteriolar dilatation (itself a result of $\beta_{2}$-adrenoreceptor stimulation) and is achieved with little alteration in the principal determinants of myocardial oxygen requirement.

\section{Introduction}

Salbutamol, a relatively specific $\beta_{2}$-adrenoreceptor agonist, improves cardiac output in patients requiring circulatory support after heart surgery. ${ }^{1-3}$ Beneficial haemodynamic effects have been shown in patients with congestive cardiomyopathy treated with salbutamol. ${ }^{4}$ Lal et $a l^{5}$ briefly reported a clinical evaluation of the drug in patients with severe left ventricular failure complicating acute myocardial infarction. We now report the effects on intravascular pressures and cardiac output in a series of similar patients during the intravenous infusion of salbutamol.

\section{Methods}

We studied 11 men, whose average age was 64 years (range 43-84). All had electrocardiographic evidence of acute myocardial infarction (seven anterior and four inferior) and radiological evidence of pulmonary oedema. Six of the patients, four of whom were in cardiogenic shock, had proved resistant to intravenous frusemide. During the study period all patients were sedated with diazepam and given

Department of Cardiology, Royal Sussex County Hospital, Brighton BN2 5BE

ADAM D TIMMIS, MB, MRCP, cardiac registrar (present address: department of cardiology, King's College Hospital, London SE5 9RS)

SARKIES K STRAK, MB, CHB, research registrar

DOUGLAS A CHAMBERLAIN, MD, FRCP, consultant cardiologist continuous oxygen treatment; five were receiving oral digoxin, and one a lignocaine infusion at a constant rate of $1.5 \mu \mathrm{g} / \mathrm{min}$. One patient with inferior infarction and $\mathrm{A}-\mathrm{V}$ nodal block was treated with ventricular pacing (rate $100 / \mathrm{min}$ ), and another was in atrial fibrillation; the remainder were in sinus rhythm.

Observations were made in the coronary care unit within 72 hours of admission. A Swan-Ganz thermodilution catheter (Edwards Laboratories Inc) was inserted into the right subclavian vein and flow guided with continuous pressure recording into the pulmonary artery. A short cannula was inserted into a radial artery. Pressures were measured using a Statham P23Db transducer with reference to sternal angle while patients reclined at $45^{\circ}$, and were recorded together with an electrocardiogram on a fibreoptic medical recorder (Cambridge Scientific Instruments Ltd). Cardiac output was measured by the thermodilution technique (Edwards Laboratories Inc cardiac output computer model $9510-\mathrm{A}$ ) using $10 \mathrm{ml}$ of $5 \%$ dextrose at room temperature. Five cardiac output readings were taken for each estimation: the first was discarded and the mean of the remainder obtained. The variation within any set of readings for the 10 patients with regular rhythm did not exceed $0.31 / \mathrm{min}(0.6 \mathrm{l} / \mathrm{min}$ for the patient with atrial fibrillation).

Salbutamol was diluted in $5 \%$ dextrose and administered by an infusion pump (Watson Marlow Ltd) through a cannula in a forearm vein. After a control period of 30 minutes, which was used to ensure that haemodynamic variables were stable, salbutamol was infused at an initial rate of $10 \mu \mathrm{g} / \mathrm{min}$. The rate was increased to $20 \mu \mathrm{g} / \mathrm{min}$ and then $40 \mu \mathrm{g} / \mathrm{min}$ at 15 -minute intervals, haemodynamic data being recorded at the end of each dose increment.

The condition of eight patients during the haemodynamic monitoring was sufficiently stable to permit brief withdrawal of the salbutamol infusion. Haemodynamic measurements were made 30 minutes later. At the end of the study all patients were treated with the lowest dose of the drug consistent with a satisfactory haemodynamic response. In some cases the regimen was modified by adding other drugs when systemic pressure was too low or pulmonary artery end-diastolic pressure too high with salbutamol alone.

We explained to the patients the reasons for the infusions and observations but did not obtain written consent. We believe that this was appropriate and in the best interests of the patients, since our main concern was to plan effective treatment on an individual basis A more formal approach might have unnecessarily increased both anxiety and risk. The protocol was approved by the ethical committee.

Student's $t$ test for paired data was used for statistical comparisons.

\section{Results}

The table summarises the haemodynamic effects of salbutamol. The cardiac index increased consistently, the highest values being reached when the infusion rate was set at $10 \mu \mathrm{g} / \mathrm{min}$ in two patients, $20 \mu \mathrm{g} / \mathrm{min}$ in three, and $40 \mu \mathrm{g} / \mathrm{min}$ in the remaining six. The mean maximum increase of $56 \%$ at these infusion rates was accompanied by a fall in systemic resistance of $39 \%$ (fig 1 ).

The change in output at the lowest infusion rate $(28 \%$ was achieved principally by an increase in stroke volume $(29 \%)$ with little alteration of heart rate. A further increase in output when the infusion rate was increased from 10 to $40 \mu \mathrm{g} / \mathrm{min}(22 \%)$ was accompanied by similar proportional increases in average heart rate $(9 \%)$ and stroke volume $(14 \%)$. This pattern, however, was not consistent between patients: in four the stroke index declined because heart rate increased more than output as the salbutamol infusion progressed from 20 to $40 \mu \mathrm{g} / \mathrm{min}$.

At the infusion rates at which the peak increase in output was reached in individual patients mean systemic arterial pressure fell slightly but significantly (average fall $6 \mathrm{~mm} \mathrm{Hg} ; \mathrm{P}<0.05$ ). The effects of salbutamol on right atrial pressure and pulmonary artery end-diastolic pressure were small at all infusion rates and did not achieve significance. 
Mean ( $\pm S E$ of mean) values of haemodynamic variables before and during salbutamol infusion in patients with left ventricular failure complicating acute myocardial infarction $(n=11)$

\begin{tabular}{|c|c|c|c|c|}
\hline & \multirow{2}{*}{ Control } & \multicolumn{3}{|c|}{ Salbutamol infusion rate } \\
\hline & & $10 \mu \mathrm{g} / \mathrm{min}$ & $20 \mu \mathrm{g} / \mathrm{min}$ & $40 \mu \mathrm{g} / \mathrm{min}$ \\
\hline $\begin{array}{l}\text { Cardiac index }\left(1 / \mathrm{min} / \mathrm{m}^{2}\right) \\
\text { Heart rate (beats/min) } \\
\text { Mean systemic arterial pressure }\end{array}$ & $\begin{array}{l}1 \cdot 8 \pm 0 \cdot 2 \\
104 \pm 8\end{array}$ & $\begin{array}{l}2 \cdot 3 \pm 0 \cdot 2 * * * \\
105 \pm 8\end{array}$ & $\begin{array}{l}2 \cdot 6 \pm 0 \cdot 2^{* * *} \\
110 \pm 7^{*}\end{array}$ & $\begin{array}{l}2 \cdot 8 \pm 0 \cdot 2^{* * * *} \\
115 \pm 6 * *\end{array}$ \\
\hline $\begin{array}{l}\text { (mm Hg) } \\
\text { Right atrial pressure }(\mathrm{mm} \mathrm{Hg})\end{array}$ & $\begin{aligned} 76 & \pm 6 \\
2 & \pm 1\end{aligned}$ & $\begin{array}{r}72 \pm 6 \\
2 \pm 1\end{array}$ & $\begin{array}{r}72 \pm 6 \\
2 \pm 1\end{array}$ & $\begin{array}{r}71 \pm 6 \\
2 \pm 1\end{array}$ \\
\hline $\begin{array}{l}\text { Pulmonary artery end-diastolic } \\
\text { pressure (mm Hg).. } \\
\text { Systemic vascular resistance }\end{array}$ & $21 \pm 1$ & $20 \pm 1$ & $19 \pm 1$ & $20 \pm 1$ \\
\hline 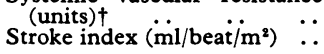 & $\begin{array}{l}23 \pm 2 \\
17 \pm 2\end{array}$ & $\begin{array}{l}18 \pm 2 * * * \\
22 \pm 3 * * *\end{array}$ & $\begin{array}{l}16 \pm 1^{* * *} \\
23 \pm 2^{* *}\end{array}$ & $\begin{array}{l}14 \pm 1 * * * \\
24 \pm 2 * * *\end{array}$ \\
\hline
\end{tabular}

†Systemic vascular resistance in arbitrary units expressed as mean systemic arterial

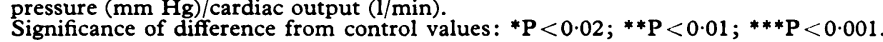

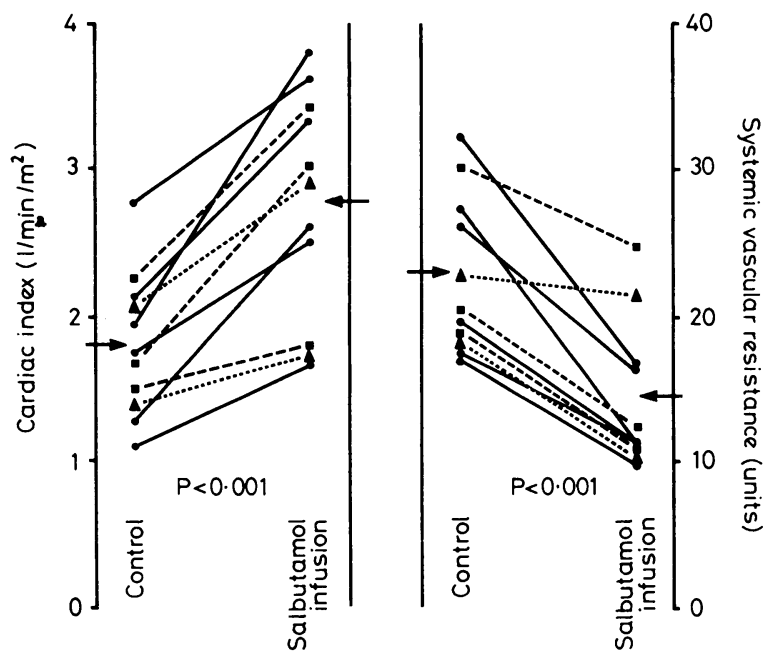

FIG 1-Maximum increments in cardiac index and corresponding reductions in systemic vascular resistance in each patient. Systemic vascular resistance expressed as mean systemic arterial pressure $(\mathrm{mm} \mathrm{Hg}) /$ cardiac output $(1 / \mathrm{min})$. Arrows indicate means. $\Delta=10 \mu \mathrm{g} / \mathrm{min}$. $\square=20 \mu \mathrm{g} / \mathrm{min} . \quad=40 \mu \mathrm{g} / \mathrm{min}$.

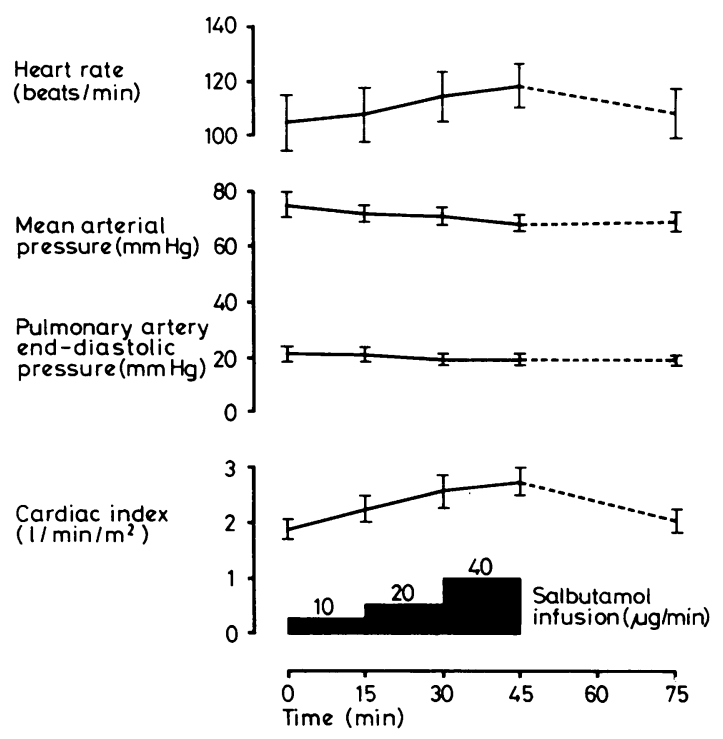

FIG 2-Haemodynamic effects of an increasing rate of salbutamol infusion in eight patients, showing mean ( \pm SE of mean) values before, during, and 30 minutes after salbutamol infusion.
Figure 2 shows the mean values of variables determined before, during, and after the salbutamol infusions in eight of the patients. These confirmed that changes reflected drug effects rather than spontaneous improvement, since all variables except blood pressure returned rapidly towards control values after the infusions were discontinued.

The haemodynamic response to salbutamol infusion in the four patients with cardiogenic shock was similar to that shown by the rest of the group. Apart from a small increase in the ventricular ectopic rate in one patient during infusions at $40 \mu \mathrm{g} / \mathrm{min}$ no other side effects of the drug were observed.

Four of these 11 critically ill patients survived to be discharged. None died within 24 hours after completing the haemodynamic measurements.

\section{Discussion}

Severe left ventricular dysfunction complicating acute myocardial infarction may manifest as pulmonary oedema or evidence of poor perfusion, which is described in extreme cases as cardiogenic shock. While "backward failure" and "forward failure" usually co-exist, one or other may dominate, the clinical manifestations depending on the degree of myocardial damage, the imbalance between right and left ventricular performance, changes in peripheral vascular resistance, and other complex circulatory adjustments. Left ventricular failure and mild low-output states usually improve spontaneously or respond rapidly to fairly simple treatment, but a poor prognosis is implied if these manifestations of left ventricular dysfunction prove refractory or worsen after early treatment. Treatment for this group of patients remains unsatisfactory, and many conventional agents are either ineffective or improve one variable at the expense of others. A dopamine infusion, for example, may induce a modest increase in cardiac output in patients with cardiomyopathic heart failure but sometimes at the cost of increased left ventricular filling pressure. ${ }^{6}$

Salbutamol has not been adequately assessed in this context. It is a fairly specific $\beta_{2}$ (predominantly vascular) adrenoreceptor agonist and is likely to cause arteriolar dilatation with a consequent reduction in left ventricular afterload. This action must have contributed appreciably to the enhanced cardiac output observed in the present series. The slight falls in blood pressure despite increased flows reflect the considerable reductions in calculated peripheral resistance shown in fig 1 ; other drugs that increase output by this type of action include phentolamine, ${ }^{7}$ sodium nitroprusside, ${ }^{8}$ and prazosin. ${ }^{9}$

We do not know whether the slight $\beta_{1}$ (predominantly cardiac) adrenoreceptor agonist effect of salbutamol ${ }^{10}$ contributed to the change in output. Sharma and Goodwin ${ }^{4}$ used the drug in patients with congestive cardiomyopathy and concluded that increases in cardiac output were due to direct inotropic activity. In some experimental preparations salbutamol acts as a strong inotrope. ${ }^{11}$ In our study, however, salbutamol infusion at $10 \mu \mathrm{g} / \mathrm{min}$ caused virtually no increase in heart rate and even at $40 \mu \mathrm{g} / \mathrm{min}$ the increase was only 11 beats $/ \mathrm{min}$. Some of this acceleration was probably reflex in origin owing to the small fall in blood pressure; allowing for this we can conclude only that salbutamol has little direct chronotropic effect on the heart in the dose ranges used and therefore is unlikely to have had important inotropic effect, since these two sympathetic influences are not readily separable. Gibson and Coltart ${ }^{12}$ came to similar conclusions in their investigation of salbutamol in patients with mitral valve disease, as did Nayler ${ }^{13}$ in experimental work on human and animal muscle preparations.

The predominantly peripheral mode of action of salbutamol in enhancing cardiac output has important implications. Treatment in acute myocardial infarction should preferably not increase myocardial oxygen requirement, for this would cause further necrosis within the jeopardised zone of critically reduced coronary perfusion. The major determinants of oxygen use $\mathrm{e}^{14}$ are heart rate, blood pressure (or wall tension), and velocity of contraction, which depends principally on sympathetic drive. Salbutamol slightly increases the first of these factors, slightly 
reduces the second, and evidently has little effect on the third: thus there is no major penalty to the heart in terms of oxygen uptake for the increased flow that is generated. With the exception of other vasodilators most agents capable of augmenting cardiac output do so at greater metabolic cost.

As with most clinical studies, some compromises were made in design to safeguard the overriding interests of the patients. We were anxious to establish the most appropriate treatment for each patient with little delay and were therefore unable to return to control conditions after each infusion rate to distinguish drug effect from possible spontaneous improvement. We thought it justifiable, however, to interrupt treatment once after the $40 \mu \mathrm{g} / \mathrm{min}$ dose regimen in eight of our 11 patients to show that the haemodynamic variables returned to the pretreatment values; only mean arterial pressure remained appreciably different from control readings in most patients. We chose to use pulmonary artery end-diastolic pressure as a measure of left ventricular filling pressure to avoid repeatedly wedging the Swan-Ganz catheter, since frequent changes in position or balloon inflation carry small risks. Though the measurement tends to underestimate true left atrial pressure in the presence of heart failure, ${ }^{15}$ the correlation between the two indices is close and changes are faithfully reflected.

Salbutamol has little effect on "backward failure" as shown by the increased pulmonary artery end-diastolic pressure in our patients and therefore cannot be recommended for the treatment of pulmonary oedema in acute myocardial infarction. It is not useful if an increase in blood pressure is believed to be essential. Our results suggest, however, that salbutamol is a useful and safe method of increasing cardiac output in those patients with myocardial infarction in whom poor perfusion is the most important haemodynamic disturbance.

Some of the cost of this study was met by Glaxo-Allenburys Research.

Requests for reprints should be addressed to Dr D A Chamberlain, Royal Sussex County Hospital, Brighton BN2 5BE.

\section{References}

1 Wyse, S D, Gibson, D G, and Branthwaite, M A, British Medical fournal, $1974,3,502$.

2 Yacoub, M H, and Boyland, E, Lancet, 1973, 1, 1260.

${ }^{3}$ Poole-Wilson, P A, et al, British Heart fournal, 1977, 39, 721.

4 Sharma, B, and Goodwin, J F, Circulation, 1978, 58, 449.

5 Lal, S, et al, Lancet, 1972, 1, 853.

6 Leier, C V, et al, Circulation, 1978, 58, 466.

7 Walinsky, P, et al, American fournal of Cardiology, 1974, 33, 37.

${ }^{8}$ Franciosa, J A, et al, Lancet, 1972, 1, 650.

${ }^{9}$ Mehta, J, et al, American fournal of Cardiology, 1978, 41, 925.

${ }^{10}$ Recent Advances in the Pharmacology of Adrenoreceptors, ed E Szabadi, C M Bradshaw, and P Bevan. Elsevier, North Holland Biomedical Press, 1978.

11 Cornish, E J, and Miller, R C, Fournal of Pharmacy and Pharmacology, 1975, 27, 23.

12 Gibson, D G, and Coltart, D J, Postgraduate Medical Fournal, 1971, 47, suppl, p 40.

13 Nayler, W G, Postgraduate Medical fournal, 1971, 47, suppl, p 16.

14 Sonnenblick, E H, et al, American fournal of Physiology, 1965, 209, 919.

${ }^{15}$ Falicov, R E, and Resnekov, L, Circulation, 1970, 42, 65.

(Accepted 23 August 1979)

\title{
The Scottish Perinatal Mortality Survey
}

\author{
GILLIAN M MCILWAINE, R C L HOWAT, FRANCES DUNN, M C MACNAUGHTON
}

British Medical fournal, 1979, 2, 1103-1106

\section{Summary and conclusions}

Perinatal deaths in single births that occurred in Scotland during 1977 were investigated by case-record analysis. Causes of death were divided into nine categories, an extended version of the Aberdeen classification being used. Out of 1012 single perinatal deaths, 265 were due to fetal abnormality, which in 140 cases was malformation of the central nervous system. Of the 747 normally formed infants, 446 weighed $1500 \mathrm{~g}$ or more, of whom 82 died intra partum and 154 were born alive. The largest single cause of death was low birth weight in normally formed babies whose mothers had no complications of pregnancy (302 cases). Of these babies, $103(34 \%)$ were growth-retarded. Rhesus incompatibility (16 deaths) and maternal diabetes (seven deaths) were not major causes of perinatal loss.

\footnotetext{
University Department of Obstetrics and Gynaecology, Royal Maternity Hospital, Glasgow G4 0NA

GILLIAN M MCILWAINE, MD, MFCM, senior registrar in community medicine (present appointment: epidemiologist, social paediatric and obstetric research unit, University of Glasgow)

R C L HOWAT, MB, MRCOG, consultant obstetrician

FRANCES DUNN, SRN, research assistant

M C MACNAUGHTON, MD, FRCOG, professor
}

These results were thought to be valuable in illustrating the main causes of perinatal mortality and directing attention to important issues. Hence a modified version of the study is being continued to see whether yearly audit by regional assessors is a feasible and practical way of monitoring trends in perinatal mortality.

\section{Introduction}

Perinatal and neonatal mortality rates are higher in the United Kingdom than in many other Western countries. Anxiety about this was highlighted in an investigation by the Employment and Social Security Subcommittee of the House of Commons. In Scotland the perinatal mortality rate has always been higher than in England and Wales, but during 1966-76 there was a dramatic fall-namely, from 29/1000 total births to 18/1000. An English study showed that social and biological changes in the maternal age, parity, and social-class distribution of births accounted for a quarter of the overall improvement in the population. ${ }^{1}$ During the decade there were many changes in obstetric and neonatal practice-for example, screening for central nervous system deformities; increased use of fetal monitoring during pregnancy and labour; greater use of induction of labour and caesarean section; and, on the neonatal side, increased use of ventilatory support and blood-gas monitoring despite little increase in medical and nursing staff. The effect of medical intervention was debatable, but greater awareness of the problems of pregnancy and recourse to induction of labour to prevent postmaturity definitely contributed to lower mortality rates. ${ }^{2}$ 